\title{
Inhalt.
}

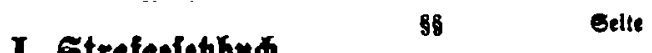

Cinleitenbe Beftimmungen

$1-12 \quad 1-5$

\section{Erifer Iril.}

Bon ber Beftrafung ber Berbreden, Bergeben unb thbertretungen tat allgemeinen.

Erjter êb|dinitt. Strafen. . . . . . . . . . 13-48 6-12

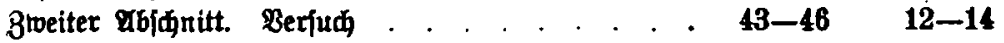

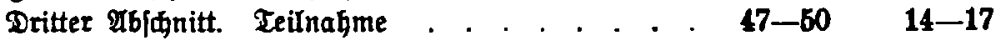

Bierter Ubjonitt. Crünbe, weldge bie Strafe aus:

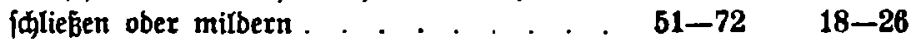

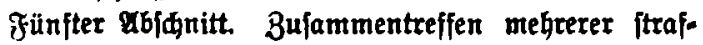
barer \$andlungen . . . . . . . . . . . . . . $73-79 \quad 26-28$

\section{3weiter Tetl.}

Bon ben einzernen Berbreden, Bergehen und

Hbertretungen un beren Beftrafung.

Erjter Mbjønitt. \$ơjberrat unb Lanbeşberrat . . 80-83 29-34

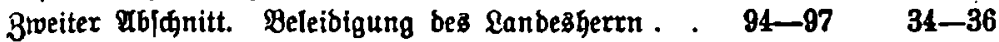

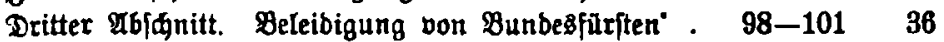

Bierter gbianitt. Feinblide Sanblungen gegen be=

freunbete Staaten . . . . . . . . . . . . . 102-104 37-38

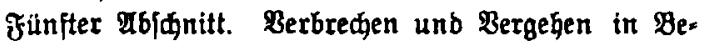

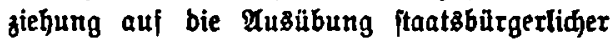

Redte . . . . . . . . . . . . . . 105-109 38-3y

Sedjiter Mbfanitt. Wiberitand gegen bie Staats.

gewalt . . . . . . . . . . . . . . 110-122 40-47

Siebenter $\mathfrak{a b i d n i t t . ~ B e r b r e d g e n ~ u n b ~ B e r g e h e n ~ r o i b e r ~}$

bie Bffentlidje Drbnung . . . . . . . . . . . . 123-145 47-58

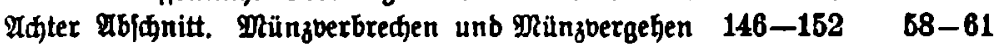

Reunter đb/ 


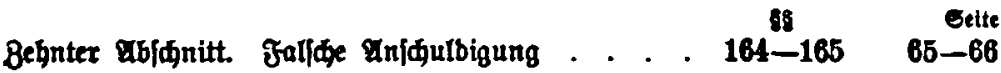

GIfter $\mathfrak{A b}$ [dnitt. Bergeber, welde fid auf bie Meligion bejiegen . . . . . . . . . . . .

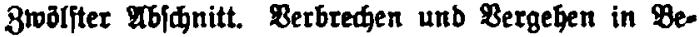
ziefung auf ben Rerjonentanb. . . . . .

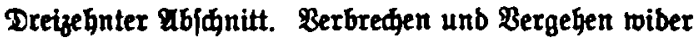
bie Sittlidpleit . . . . . . . . . . .

Bierzebnter Qbjignitt. Beleibigung . . . . . .

Funfzehnter 9bidnitt. Zweilampf . . . . . . . .

Sedzekgnter צbjdnitt. Berbreden unb Bergehen wiber bas seben. . . . . . . . . . .

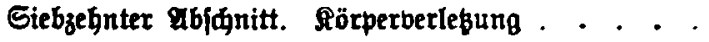

פabtzehnter ab[dnitt. Berbredgen und Bergegen wiber bie perföntidge freiheit . . . . . . . .

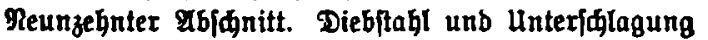

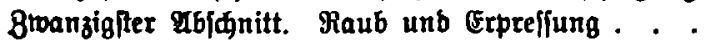

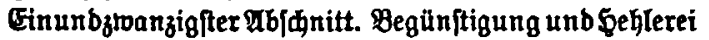
3weiunbzwanzigfter $\mathfrak{2 b}$ bdnitt. Betrug und untreue . Dreiunbztwanzigiter $\mathfrak{T b}$ bjonitt. Urfunhenfarjajung. .

Bierunbzwanzigfter $26[$ jhnitt. Banterott(aufgehoben) $\mathfrak{R D}$.

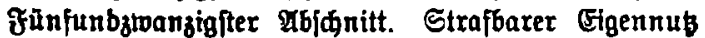
unb Berlęung frember Beheimniffe . . .

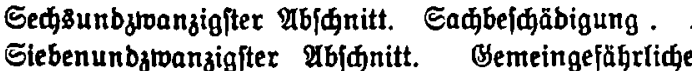
Betbreden unb Bergegen . . . . . . .

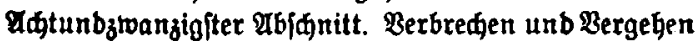
im rimte

$166-168 \quad 66-68$

$169-170 \quad 69-70$

171-184b $\quad 70-81$

$185-200 \quad 81-88$

$201-210 \quad 88-90$

211-222 91-96

223-233 97-104

234-241 104-109

242-248 110-118

$249-256 \quad 118-122$

257-262 122-126

263-266 126-132

$267-280 \quad 132-140$

$239-244 \quad 140-143$

$284-302 \theta \quad 143-158$

$303-305 \quad 159-160$

$306-330 \quad 161-174$

$331-359 \quad 174-187$

Reununbztwanzigfter $\mathfrak{a b j}$ initt. hbertretungent . . . 360-370 187-208

\section{Iuharg.}

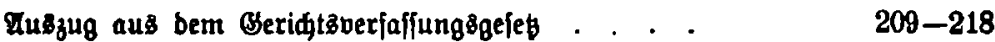

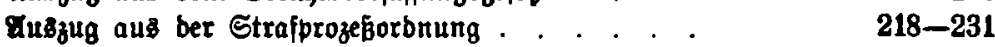

Sadregifter . . . . . . . . . . . 232 